\title{
Internship Partners for Long-Term Care Administrators - A Model Sustainable Through COVID-19 Is a Model for the Future
}

\author{
Lindsey J. G. Creapeau \\ University of Wisconsin - Eau Claire \\ Jennifer L. Johs-Artisensi \\ University of Wisconsin - Eau Claire
}

Most long-term care administration programs require an internship as a graduation requirement. The University of Wisconsin - Eau Claire's Health Care Administration interns are highly valued by partner sites, hosting students annually. In the 2019-2020 academic year, 59 students were nine months into their internship experience when COVID-19 disruptions became widespread. This paper describes the program's immediate and multifaceted response, which led to exceptional outcomes. Lessons learned suggest that through effective planning and exceptional reaction in the face of adversity, strong academic programs and partnerships play a key role in alleviating long-term care workforce challenges by producing extraordinarily prepared future leaders.

Keywords: COVID-19, long-term care, workforce, pandemic response, internship

\section{INTRODUCTION}

The number of seniors in the United States of America is rapidly increasing. Each day, approximately 10,000 people turn age 65 (United States Census Bureau, 2019). While the majority of the U.S. population lives in a home or community-based setting, the chance that a person will reside in group living quarters (e.g., skilled nursing or assisted living) rises with age (United States Census Bureau, 2018). As such, welltrained administrators are needed to provide leadership for health care settings.

The field of long-term care administration is seeking emerging leaders (Olson, 2018) as administrators age (Castle, 2001) and more leave the field than enter (Tellis-Nayak, 2007). With the long-term care administration career generally requiring a bachelor's degree in addition to administrator-in-training experience (Center for Health Work Force Studies, 2004), the profession needs four-year universities to provide foundational knowledge to students and foster partnerships with external entities. These preparatory practices set the stage for quality experiences for students and assist in the goal of bolstering the number of well-qualified leaders entering long-term care administration.

The University of Wisconsin - Eau Claire Health Care Administration (HCAD) program provides strong groundwork for those training to be administrators in a variety of health care service organizations (Health Care Administration, 2021). After completing on-campus courses, students spend 50 weeks completing an offsite, structured internship (also referred to as a practicum) at a skilled nursing facility. In 
a typical academic year, the university places between 50-65 students at internship sites primarily located in the Midwest region of the country.

This internship experience is designed to be mutually beneficial to both students and partnering sites. Students obtain knowledge and skills needed to become an administrator upon graduation, and as such are well-prepared to enter a leadership position, even at a young age. Additionally, hosting a student is advantageous to the site. Partnering sites understand students are arriving with a solid educational foundation and can provide fresh perspective to the organization. With students present for 50 weeks, interns are able to provide significant contributions to the organization throughout their time on site. Partnering organizations pay students a stipend for the duration of their internship, benefitting both parties: students get assistance with living expenses and sites can maintain reasonably high expectations for their students. Last, internship sites and their management teams are reassured that the HCAD program is available for support during the year-long experience.

\section{PURPOSE}

The UW - Eau Claire HCAD program has been a leader in the field for many years. However, the inception of the COVID-19 pandemic caused disruption in all facets of operations. The pandemic required immediate modification of normal practice and illustrated the essential nature of future preparedness, in line with the greater health care community's experience (Adalja et al., 2020). Despite upheaval, the program had a successful outcome.

In the 2019-2020 academic year, 59 students were nine months into their year-long internship when COVID-19 interferences became widespread. UW- Eau Claire's HCAD program response was immediate and multifaceted, comprising 1) mitigation of fears, concerns, and challenges of students, preceptors, and host sites, 2) substantial communication with university leadership on liability and appropriate course of action, and 3) development of COVID-19 policies for the program. The following case study will reveal the methodology of each response and provide a model of practice that can be replicated by other programs.

\section{METHODS}

The UW- Eau Claire HCAD program response consisted of multiple interrelated processes, including program/position responsibilities, communication, and policy development.

\section{Program Structure and Position Responsibilities}

The HCAD program includes four full-time faculty members. Three positions are tenure-track professorial positions (one of which also holds a Program Director role). The fourth is a dedicated Practicum Coordinator/instructor position. The Practicum Coordinator role is an academic interface between students, host sites, and the university; the individual in this position is primarily responsible for coordination and communication with students during their internship year. The Practicum Coordinator and Program Director frequently collaborate to develop, maintain, and/or modify student/program responsibilities. As such, the individuals in these two positions were primarily responsible for the program's COVID-19 pandemic response.

\section{Mitigation of Fears, Concerns, and Challenges}

The COVID-19 pandemic led to unprecedented fears, concerns, and challenges for both practicum students and long-term care sites. Many students feared a COVID-19 infection themselves as much was unknown about the illness. Several expressed to the Practicum Coordinator that they were considering leaving their internship for safety reasons. The Practicum Coordinator spent significant amounts of time conversing with students individually (via email, phone, and videoconferencing), reassuring them that infection control policies followed by their sites (e.g., temperature/symptom screening, prohibiting nonessential personnel, disinfecting, personal protective equipment) were implemented to keep employees as safe as possible, and due to all these policies and precautions, the health care environment may be safer 
than non-health care workplaces. At the time, primary concerns for adverse virus outcomes focused primarily on the elderly population that students were caring for, rather than the general public, so this message was reiterated.

During the onset of the pandemic, some students expressed concern over being overworked in their roles. As they were near completion of the practicum year, sites were utilizing students in leadership roles and, therefore, requesting significant amounts of overtime work, causing feelings of burnout. During their internships, students typically average 40-45 hours/week on site, while also completing faculty-led online courses as full-time students (Johs-Artisensi \& Olson, 2017). In the early days of the pandemic, students were often working near 60 hours/week. The Practicum Coordinator spoke with students and preceptors frequently, reminding them that while they were learning incredible leadership lessons, the students also needed to protect their well-being and time so as to remain eligible for graduation through satisfactory academic performance. Balancing workplace demands and well-being is an important and sometimes difficult skill for new administrators to develop. So, not only did this offer another important learning experience, but also students and preceptors were ultimately able to return to standard work schedules with this support.

An additional challenge developed related to internship hour requirements. As one of 16 schools accredited by the National Association of Long Term Administrator Boards (NAB) (National Association of Long Term Care Administrator Boards, n.d.), UW- Eau Claire's HCAD program is required to include 1000 hours of on-site practicum experience; at outset of the pandemic, students had already met that requirement. However, as a program approved by the Wisconsin Department of Safety and Professional Services, UW - Eau Claire requires a 2000-hour internship to meet state nursing home administrator licensing requirements. With many uncertainties of whether students would be able to continue their internships, both students' graduation and licensure abilities could be jeopardized. The Practicum Coordinator quickly disseminated information to students and preceptors about these requirements in hopes that students would be allowed to remain on site until the end of the practicum year. This was especially important as some sites were debating whether students were considered "essential" at their sites.

With so many unknowns at the outset of the pandemic, facilities serving as practicum sites had to quickly determine whether students could be considered essential workers. The term essential workers, referring to those required to continue critical infrastructure operations, rapidly and continually shifted in the first months of the pandemic (Cybersecurity and Infrastructure Security Agency, 2020). As students had been on site for nine months, they were already acting in leadership roles and able to provide support to their team in a multitude of ways. The Practicum Coordinator had many conversations with both students and preceptors to provide rationale for how and why students could remain on site. Most sites were able to immediately justify their support of the position and continue the internship, but two preceptors initially indicated they would dismiss their student. The first preceptor believed the student role fell under a volunteer role, but discussions with the Practicum Coordinator aided in reclassification. The second preceptor wanted to remove the student more out of a motherly concern about the student's safety. After conversations with the Practicum Coordinator, she acquiesced, realizing the student was adamantly choosing this career and needed to continue in order to remain eligible for licensure.

Overall, substantial communication with students and preceptors, led by the Practicum Coordinator and supported by the Program Director, offered significant support to all parties through an extraordinary and ambiguous circumstance.

\section{Communication With University Leadership}

At the outset of the pandemic, the Practicum Coordinator and Program Director acted autonomously to make rapid decisions for the students and program. However, as COVID-19 quickly spread throughout the country, UW- Eau Claire leadership needed updates on how the situation was unfolding. Multiple phone conversations and videoconferences with the Department Chair and Dean and the Office of Risk Management and Safety helped to determine how other programs in similar situations (e.g., nursing, teacher education, professional program internships) were adjusting to programmatic and licensure requirements. It seemed that some students were able to stay on site (e.g., business operations in critical supply sectors), 
some were continuing internships remotely (e.g., accounting, teacher education), and some were being dismissed from internships (e.g., nursing students in lower-level courses who were doing more "observing" than assisting and using valuable personal protective equipment).

Initial concerns were related to HCAD students' abilities to remain on site relative to licensure requirements, but also expanded to include exploration of any potential university liability. Ultimately, the HCAD program, Department Chair, and Dean were informed that the university's policy (per the Risk Management department) would be to defer to the host site's directives on keeping students. If the host site was willing to continue hosting students (all sites were), HCAD students could determine whether they wanted to remain on site. As these students wanted to become health care leaders, as evidenced by their choice of major, and it was ultimately their decision to continue forward in the internship.

\section{Development of COVID-19 Policy for Program}

After university leadership directives to defer to the host site were final, and practicum sites indicated their desire to continue hosting students for the remainder of the year, the Practicum Coordinator and Program Director developed a policy related to COVID-19 impacts. It was anticipated that issues might continue to arise (e.g., student concerns/fears, site fears as COVID-19 cases increased, etc.), and as such it was imperative to have a unified message from the program and to all students. The policy was a set of standards that the HCAD team could refer to rather than a standardized message, so that it could be adapted and tailored as necessary (and dependent on specific situations). The Coordinator and Director determined that if students wanted to leave their internship for any reason (e.g., felt uncomfortable, felt unsafe, realized that this career choice was not what they expected), they would not be compelled to stay, and alternatives could be offered. First, the student could pause their internship and would be assisted in finding a new site later, after the pandemic ended, to complete their hours at a later date (delaying graduation). Second, students could change their major to a general business administration major with a gerontology or public health minor, with assistance from the Department Chair; this option would have allowed students a path to graduate as planned at the end of the semester. Some students briefly entertained these possibilities, but ultimately all opted to remain on site, complete their internship hours, and graduate with the HCAD major.

\section{RESULTS}

Results of this approach led to exceptional success as $100 \%$ of practicum students remained on-site for the final three months of their internship year. All 59 students completed their required 2000 hours of internship experience within the typical 50-week senior year. Students received incredible leadership lessons in regulation, crisis management, infection control, resident-staff and resident-peer relationships, the value/impact of communal activities/dining on resident well-being, communication, etc. At the close of their practicum experience, students completed a practice NAB licensure exam (as part of the UW- Eau Claire HCAD curriculum) and earned higher scores than any prior cohort. Upon graduation, students were extraordinarily marketable and prepared to lead their new employers' organizations.

Despite the unknown future of COVID-19 (longevity of virus in long-term care, financial prospects of partner organizations, etc.), practicum host sites continued to accept students in the future practicum student cohort, ready to begin their internships three months after COVID-19 disruption began. All 54 students in the 2020-2021 cohort began their internships as scheduled and plans for placing the 2021-2022 cohort continued throughout the summer of 2020 without interference. Internship sites continue to partner with the program as their organizations recognize the value of hosting students.

\section{DISCUSSION}

The UW - Eau Claire HCAD program had several lessons learned and reinforced during the COVID19 pandemic and associated response. The pandemic had significant impact on the educational institution and on health care facilities (and therefore those training to lead the health care workforce). Yet, the frontend preparation of the academic program allowed it to withstand unforeseen and cataclysmic effects of the 
pandemic with optimism toward continued and future practices. As such, two recommendations to other programs include a clear delineation of responsibility in each role and the establishment (or continued support) of a Practicum Coordinator-type role. This role allows for a single point of contact for students completing internships and for internal/external partners. When a crisis arose, having someone in this position assisted in eliminating confusion and allowed for consistent response to all stakeholders. There was one point-person, a known contact for all parties; the program had a clear lead identified in the area of responsibility.

A second lesson that was reinforced was the critical importance of strong partnerships in a health care program. Longstanding relationships with practicum sites and preceptors established prior to the pandemic allowed organizations to feel confident in the support and guidance they would receive throughout a time of incredible uncertainly. Preceptors felt comfortable asking the Practicum Coordinator difficult questions and talking through various scenarios. Relationships with university administration prior to the pandemic allowed leadership to feel confident that the Practicum Coordinator and Program Director were knowledgeable on licensure, industry, and graduation requirements and were acting in the best interest of student success and overall well-being. One recommendation to other programs is to build and maintain solid relationships with all partners (internal and external) to gain trust and ensure confidence in each party through times of uncertainty. A second recommendation is to consider all stakeholders' needs in decisionmaking, as it will maintain, strengthen, and enhance the partnerships. Overall, these strong partnerships collaborated to achieve a mutually-valuable experience for all involved parties (students, preceptors, organizations, and the university).

A third and final takeaway from the experience is the importance of a swift and nimble response to all involved stakeholders in the face of a crisis. With so many uncertainties, the speed with which the university provided guidance to students, preceptors, and host sites was critical. The Practicum Coordinator and Program Director spent significant amounts of time outside of their typical responsibilities, focused on communication and planning, in order to respond and provide timely guidance to all stakeholders. As crisis situations can increase the need for leadership and guidance in emergent situations (Weick, 1995), this rapid response allowed stakeholders to feel supported from the outset of the pandemic.

Through effective planning and exceptional reaction in the face of extreme adversity, strong academic programs play a key role in alleviating long-term care workforce challenges by producing extraordinarilyprepared future leaders.

\section{REFERENCES}

Adalja, A.A., Toner, E., \& Inglesby, T.V. (2020). Priorities for the US health community responding to COVID-19. JAMA, 323(14), 1343-1344.

Castle, N. (2001). Administrator turnover and quality of care in nursing homes. The Gerontologist, 41(6), 757-767.

Center for Health Work Force Studies. (2004). A legal practice environment index for nursing home administrators in the 50 states. Rensselaer, New York.

Cybersecurity and Infrastructure Security Agency. (2020). Identifying Critical Infrastructure During COVID-19. Retrieved September 5, 2020, from https://www.cisa.gov/identifying-criticalinfrastructure-during-covid-19

Health Care Administration. (2021). Retrieved from https://www.uwec.edu/academics/programs/undergraduate/health-care-administration/

Johs-Artisensi, J.L., \& Olson, D.M. (2017). A long-term care administration internship cohort model with adjunctive applied, online coursework. Journal of Health Administration Education, 34(4), 639649.

National Association of Long Term Care Administrator Boards. (n.d.). Listing of NAB accredited colleges and universities. Retrieved October 11, 2021, from https://www.nabweb.org/nab-accreditedcolleges-and-universities 
Olson, D.M. (2018). A framework for expanding and enhancing university-based health administration and aging services programs across the United States. Seniors Housing and Care Journal, 26(1), 83-95.

Tellis-Nayak, V. (2007). The satisfied but disenchanted leaders in long-term care: The paradox of the nursing home administrator. Seniors Housing and Care Journal, 15(1), 4-18.

U.S. Census Bureau. (2018). The population 65 years and older: 2016. Retrieved August 22, 2020, from https://www.census.gov/library/visualizations/interactive/population-65-years.html

U.S. Census Bureau. (2019). By 2030, all baby boomers will be age 65 or older. Retrieved August 20, 2020, from https://www.census.gov/library/stories/2019/12/by-2030-all-baby-boomers-will-beage-65-or-older.html

Weick, K.E. (1995). Sensemaking in Organizations. Thousand Oaks, CA: Sage Publishing. 